\title{
Research of the Operational Mechanism of the Fresh Food E-commerce Supply Chain and "Agricultural and Supermarket Docking" Mode in China
}

\author{
Juntao Li, Xiaohuan Xiang, Xingxiang Tao \\ School of Information, Beijing Wuzi University, Beijing, China \\ Email address: \\ 862974337@qq.com (Juntao Li),313809457@qq.com (Xiaohuan Xiang),260486736@qq.com (Xingxiang Tao)
}

\section{To cite this article:}

Juntao Li, Xiaohuan Xiang, Xingxiang Tao. Research of the Operational Mechanism of the Fresh Food E-commerce Supply Chain and “Agricultural and Supermarket Docking” Mode in China. Science Research. Vol. 4, No. 2, 2016, pp. 55-60. doi: 10.11648/j.sr.20160402.16

Received: March 15, 2016; Accepted: April 1, 2016; Published: April 25, 2016

\begin{abstract}
As an emerging field of e-commerce in China, fresh food e-commerce is still in the development period. In order to facilitate an in-depth study, this paper summarizes the operational mechanism and the characteristics of the fresh food e-commerce supply chain, and proposes suggestions about fresh food e-commerce operation and development. One of the challenges in the implementation of "agricultural and supermarket docking" mode is that fresh agricultural products circulation is not fluent. Public information service platform enables the enterprise information resources sharing within the scope of supply chain. It uses information technology tools to integrate the involved enterprise's information resources in supply chain with Internet advantages. In the logistics business, under the premise of sharing of information, retail supermarkets and third party cold chain logistics services company combine business situation and adjust the logistics business process. In the process of circulation of agricultural products, it works together in the process of transportation and distribution of agricultural products based on the public information service platform in both orders and waybill operation independently. Its systematic operation includes cold chain transportation and cold storage resource, reducing their operating cost, improving the benefit of enterprises and improving the service level. Through the application of Internet technology, it can solve the traditional information service platform of the quality of agricultural products and transportation problems.
\end{abstract}

Keywords: Fresh Food E-commerce, Operating Mechanism, Public Information Service Platform, "Agricultural and Supermarket Docking" Mode

\section{Introduction}

In recent years, both researches and practitioners have devoted attention to environmental sustainability of supply chain, while firms have modified their marketing strategies highlighting green practices in productive and logistic processes among the features of their products [1]. Fresh agricultural product is highly perishable. Its geographical distribution is wide-ranging. So there is a huge difference compared with standardized, large-scale, full circulated industrial commodities. Therefore, the time utility of fresh agricultural product is particularly strong, with the increase of selling time, showing rapid decline in product prices. Fresh agricultural product is closely related to production and market demand. The economic developed rapidly, the quality of life improved continuously, promoting the rapid expansion of the market of fresh agricultural product industry. Figure 1 shows the future fresh market capacity in China. The fresh food industry is increasingly more interested in developing efficient and innovative solutions to guarantee quality and distribution sustainability [2].

Although fresh and cold chain logistics technologies can play a role, but the wastage of the fresh agricultural product is still very high and serious between dealers. Especially trans-regional trade deals are becoming more prominent with the stocks and the limited operational resources [3]. Currently, consumers become more and more sensitive to whether for food prices, qualities or origins, as well as the services. Consumers' buying habits are constantly changing. Changes happened in consumer behavior patterns which require fresh agricultural product more excellent in processing and circulation processes. It can be said that the one who can accurately grasp the needs of 
consumers and have rapid response based on scientific business models, then he could hold the key to improving the competitiveness of enterprises, which is supply chain management competition in the field of management.

In the traditional management, agribusiness management is based on static management of order-driven, the information on the fresh agricultural product trade channels is non-smooth, the price is vicious gaming. It is clear that their own way of trading has been difficult to meet fast-changing market needs, information sharing and overall cooperation between enterprises is critical. Agricultural market network infrastructure is not perfect. The spread of information service is not fast. Information resource of circulation and consumption is not enough [4]. With the development of internet technology, fresh agricultural product enterprises can integrate supply chain and implement professional organizations by means of e-commerce, so that enterprises can make full and efficient use of resources, work together effectively and reasonably, so as to improve the competitiveness of agriculture-related enterprises.

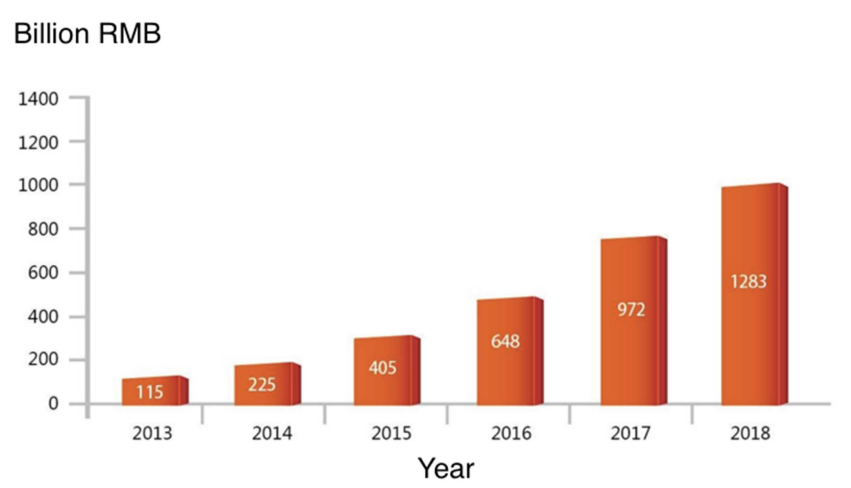

Figure 1. The future fresh food market capacity in China.

In recent years, with the promotion of agricultural technology, major changes happened in the supply and demand of agricultural products, yet at the same time, the weak foundation of agriculture information in China leads to fruit and vegetable quality and safety problems.

With constantly improving of consciousness on food security, through information technology on agricultural of circulation process of information for track, it can guarantee agricultural quality security, providing consumers excellent agricultural products. Through information technology on agricultural information, we can timely check problems, find related responsibility people, avoid causing bigger problems. Because of the complex patterns of supply and demand, agricultural production area and demand area have huge differences in layout, resulting in the large number of intermediate wholesalers. Insecurity in all aspects influences the quality and safety of agricultural products from beginning to end, directly affect people's health.

"Agricultural and supermarket docking" mode means that retail supermarkets replace the role of wholesaler in traditional agricultural product circulation, reduce circulation costs and harmful quality and safety factors. And by using a variety of techniques and methods to achieve agricultural monitoring and management throughout the life cycle is an important way for us to solve the problems of agricultural products quality. Information tracing is one of the most effective means of control.

It will be full monitoring and managing of agricultural products from the origin to the consumption place, by achieving the traceability of identity information and circulation information.

\section{The Analysis About Fresh Food E-commerce Supply Chain}

The fresh agricultural product trade links includes production, purchasing, processing, selling, logistics, home delivery and so on. Along the supply chain of a product, enterprises can interconnect to any other nodes, to form a link structure which can share information and promote other enterprises.

In the fresh food e-commerce supply chain, every node integrate related enterprise information and the process supported by information technology, do research about each code in the supply chain with systemic views, and establish a strategy cooperation partners relationship which information shared and interests shared, to reduce information "island" phenomenon in product circulation, to reduce total supply chain inventory cost and trading cost between enterprises, eventually to improve efficiency in market running.

In accordance with the idea of system integration of the value chain, through information technology, we can make traditional fresh food e-commerce supply chain evolve into a goal-driven organization. The union is dominated by core enterprise, providing competitive fresh products.

\section{The Characteristics of the Fresh Food E-commerce Supply Chain Model}

There are 5 characteristics of the fresh food e-commerce supply chain model:

\subsection{Based on Synergy and System}

Fresh food e-commerce supply chain devotes to build a multi-channel value-added chain, because of a lot of professional restrictions in the area, there are many opportunities about collaboration, communication and information management. In this way, operational activities like all procurement and sales activities can be most effectively supported in the core enterprise or third party logistics and fourth party logistics management through information platforms (such as e-commerce platform).

\subsection{C2B Principle}

C2B concept is to make the enterprise consider from consumer demand, dig deeper into the customer psychology, guide by customer demand in the supply chain management, while driving the efficient operation of capital flow, material flow and information flow. 


\subsection{Quick Response Mechanism}

There will be rapid change in fresh food market demand under certain rules. That is why all the nodes of the supply chain businesses should have rapid response capability, so as to improve the efficiency of the whole system.

\subsection{Value Added Feature}

The node enterprises on supply chain make the sales planning and forecasting basing on the entire supply chain system, as well as through the coordination of all aspects of operations to meet changing market demand, make upstream enterprises and terminal enterprises ready to gain the initiative in an increasingly competitive market.

\subsection{Feature of Intersection}

In a supply chain, different types of enterprises can obtain resource from a same enterprise, an enterprise also can obtain services from a number of companies. Each node is connected, forming a cross-network structure.

\section{The Operational Mechanism of the Fresh Food E-commerce Supply Chain}

The operational mechanism of the fresh food e-commerce supply chain consists of the following 4 functions:

\subsection{Replenishment and Distribution Between the Demand and Supply Enterprises}

At first, end retailers will do the forecast according to market demand, and then pass demand information to the upstream market, and issue a notice of demand through the order management system. At last, upstream enterprises make agricultural production and distribution plan in a timely manner, using management systems and production management system, according to market demand.

We can implement replenishment and distribution system through the following three steps:

1. Terminal selling organization pass remaining inventory, shipping information and other information on to the fixed agricultural products suppliers every day through electronic commerce.

2. The fresh food suppliers collate and analysis the information, and type-in selling database system, estimate replenishment requirements, and then type-in the information in your ERP system, work out a feasible order combined with their own inventory, pass the order information to downstream distributors.

3. Downstream distributors and retailers work out a feasible order according to the supplier and they arrange shipments.

\subsection{Publish Reverse Demand}

In many cases, there are certain unstable product supply channels existing in terminal retail organization. At this time with supply chain platform, terminal retailers can publish their own listings. The suppliers or intermediary organizations in a supply chain can put their inventory information to the terminal vendors in order to get a quick react. Similarly, retail and processing companies can promptly transmit the shortage of information to suppliers by supply chain when in the absence of raw materials of agricultural products and standard products. In this way, the upper reaches of the wholesale markets and other vendors will make quick response to retail and processing companies based on their own fresh product storage conditions, so as to reduce transaction costs.

\subsection{Publish Supply and Demand Information}

Terminal retail organization can release requirement information to the upstream suppliers through the supply chain platform, organize the sales, also the upstream enterprise can release supply information at any time, to ensure the normal operation of the entire supply chain.

\subsection{Joint Distribution}

In the traditional mode, supermarkets tend to purchase through all the wholesale markets by all the logistics company, due to the time lag and location issues. This will create a lot of resource waste. Therefore, through supply chain e-commerce technology platform, we can efficiently avoid duplication of logistics and reduce transaction costs between firms.

\section{The Suggestions About Fresh Food E-commerce Operation and Development}

Fresh food e-commerce is a very complex business, which penetrate into the base from the upper reaches. The middle companies control logistics, the terminals grab the user group, ultimately reduce attrition rates and improve the delivery experience, control the logistics cost. In order to improve the efficiency of supply chain management, the company needs to undertake strict checks on product quality and make difference on the product category [5].

Product quality is the lifeline of fresh food e-commerce. Either purchasing agricultural products from agricultural product bases or managing farm themselves, the most important is formulating a fresh food product standard and testing all aspects of the work. The process must be open and transparent especially in fresh food planting, picking, inspection, processing and ensure stable supply of quality, such as the use of radio frequency identification devices technology. Let the consumers trust the company, in order to win the market [6].

To a great extent, the value of fresh food lies in its freshness. So we need to make reasonable design of logistics management and distribution. Therefore, the fresh food e-commerce which is opted for third-party logistics companies should evaluate their level of logistics services, supervise the logistics and distribution activities. The 
e-commerce which is selecting import logistics should make full use of social resources, and spend enough money and manpower in conducting the operation. In terms of value added services, we should choose combine the flexible sales approach and differentiated services.

At present, there are several good ways including membership, community supported agriculture, advance booking, group buying, etc. Secondly, providing differentiated service. The attraction of fresh food e-commerce for users largely depends on the service differentiation. We can provide personalized service for different target customers in order to meet the diverse needs of customers, which helps establish the credibility and reputation of the enterprise, so as to enhance brand loyalty.

\section{6. "Agricultural and Supermarket Docking" Mode Overview}

"Agricultural and supermarket docking" mode is a new distribution mode. The farmers and retail supermarkets signed an agreement, established strategic partnerships, provided fresh products directly by the farmer to the retail supermarket.

In other developed countries, "agricultural and supermarket docking" mode has become a mature model in fresh agricultural products market. In the United States and European countries, the penetration rate of "agricultural and supermarket docking" mode has reached more than $80 \%$, while domestic retail supermarket is less than $15 \%$. With the development of market economy, the small-scale peasant economy of production based on the family unit has become increasingly difficult to adapt the changes in market demand. "Agricultural and supermarket docking" mode promotion as a new circulation mode is imperative. And it shows how risk management and collaboration amongst stakeholders can increase chain resilience [7].

\section{Analysis of the Main Body About "Agricultural and Supermarket Docking" Mode}

The purpose of the implementation of the public information service system is to meet the business needs of clients. Therefore, combined the actual current demand for information service object, this paper mainly analyses the rural cooperatives, retail supermarkets, cold chain logistics service companies and consumers.

\subsection{The Rural Cooperatives}

Farmer is the source of agricultural product supply chain. Rural cooperatives as professional business communication organizations ease the professional gap between farmers and retail supermarkets, to a certain extent. One of the duties is to obtain real-time detailed information of orders production in retail supermarket through platform, meet offline production needs. The second is trading online with retail supermarket on behalf of the production farmers, to decrease complex degree of trading and guarantee the tracing for quality grade problem in follow-up retail supermarket.

\subsection{Retail Supermarkets}

Retail supermarket information resources system is divided into two major parts, internal information resources and external public information resources. Internal information resources refer to chain supermarket which has established cooperation relationship with production base, and logistics resources and supplier relationship resources. With reforming traditional procurement mode, it can achieve "agricultural and supermarket docking" mode of online supply, procurement, real-time trading, and establish third party cold chain logistics cooperation enterprise, put these internal resources into supply chain management. External information resources refer to release information about products supply and demand, price, and third party cold chain resources through various agricultural cold chain public information platform.

Retail supermarkets have most business intersects with other participants as the terminal enterprise in "agricultural and supermarket docking" mode. There are two main areas in information requirements for building cold chain public information service platform. One area is for rural cooperative. It can timely get the information of agricultural production, the quality of agricultural products and marketing information, grasp the information of production capacity and layout, promote circulation through the establishment of sustainable and stable supply relationships. The other is for third party cold chain logistics distribution enterprise. Cold chain resources in some retail supermarket are mainly used for meat, seafood and other products of high value goods, and limited space is used for agricultural cold chain based on high cold chain equipment input cost and operation cost. Through the integration of its own resources and third-party cold chain logistics resources, we can effectively reduce inventory costs and operating costs while ensuring product quality and increasing economic efficiency.

\subsection{Cold Chain Logistics Service Companies}

Cold chain logistics service providers in this context, refers to third party companies that provide fresh food cold chain services. Based on the advantages of circulation patterns, cold chain logistics enterprises only serve farmers and retail supermarkets. The simplified transportation links are big advantages. Despite the large initial input in cold chain enterprise, we can meet operating cost of input by establishing long-term cooperation relationship with supermarket. Through logistics public information service platform, we timely understand cold chain distribution information. With increased cooperation, we can have strategic partnership with the retailer to establish long-term stable cooperative relations. More integrated evaluation of cold chain performance is key for developing a more resource-efficient, energy-smart food supply chain [8]. Monitoring the real-time temperature, humidity, and physical position status of goods is vital in the 
cold chain. Diverse logistics technologies and systems have been adopted in the cold chain for monitoring perishable goods. However, these technologies and systems are independent from each other. Data and information in them are not integrated so that information control is not effective [9]. The cold chain assessment is designed to measure the effectiveness of the cold chain management process. Through the assessment, gaps are identified, issues are raised, and risks are determined. Upon completion of the assessment, management will have a good perspective on where resources should be deployed in addressing cold chain risks. The assessment is actually the first part of the overall cold chain management process [10].

\subsection{Consumers}

The consumers' demand of quality requirements about agricultural products is higher. Based on the advantage of RFID technology, we can solve the initial ownership of agricultural products at the same time, record the cultivation information, track the information, guarantee the safety of food.

Compared with the traditional mode of production, distribution and sale, the "agricultural and supermarket docking" mode greatly reduces the circulation time. Information transmission in the circulation is more quick, and complete the information sharing between subjects. Since proposed "agricultural and supermarket docking" mode, it gradually became three species mode, "farmers + rural professional cooperatives + supermarket" mode, "farmers + supermarket" mode and "farmers + enterprise + supermarket" mode, such as Carrefour retail supermarket and Metro retail supermarket used first species circulation mode.

The application of "agricultural and supermarket docking" mode is shortening the supply chain, simplifying the provisioning process, improving supply-chain efficiency. But there is a big difference in thoughts about operation, finance, business management and organizational level between China's farmers and supermarkets, making the mode didn't get the expected results. Considering the current situation of farmers and supermarkets, we can only use the Internet and emerging technologies to solve the problems in the model.

\section{Research of Cold Chain Function of Public Information Service Platform}

At present, one of the challenges faced by agricultural products is that circulation information is not clear. The main part of traditional cold chain information platform for public service is cold chain operations in various business areas and cold chain logistics personnel.

According to information transfer process, the platform will be divided into three main areas: one is retailer information integration and perfection of production orders. The second is data between retail supermarket and third-party cold chain logistics service provider, such as retailer order information, ex-warehouse information, storage information and third party tracking information. The third is traceable information of agricultural products based on RFID technology. The data in the center database is mainly from the above three parts. Shared database is used to collect, process and storage various shared data, and provides information shared service for rural professional cooperatives, third party cold chain logistics enterprise and retail supermarket. It will extract the above logistics data out, form a shared database.

\section{Conclusion}

This research is solving the quality problem with the rapid development of Internet technology under the background of the immature operation environment. The Internet of things technology applied in the cold chain logistics information service platform, on the other hand, considers that the characteristics of the limitation period of fresh agricultural products is short, and a serious loss of agricultural products. Through GIS/GPS techniques and sensor technology, real-time monitoring of transit transportation and distribution process can solve the problem of loss of fresh products in the process.

\section{Acknowledgements}

This paper is supported by the Funding Project for Technology Key Project of Municipal Education Commission of Beijing (ID: TSJHG201310037036); Funding Project for Beijing key laboratory of intelligent logistics system; Funding Project of Construction of Innovative Teams and Teacher Career Development for Universities and Colleges Under Beijing Municipality (ID: IDHT20130517), and Beijing Municipal Science and Technology Project (ID: Z131100005413004); Funding Project for Beijing philosophy and social science research base specially commissioned project planning (ID: 13JDJGD013).

\section{References}

[1] Matteo M. Savino, Riccardo Manzini, Antonio Mazza. Environmental and economic assessment of fresh fruit supply chain through value chain analysis. A case study in chestnuts industry [J]. Production Planning \& Control, 2015, 261.

[2] Daria Battini, Martina Calzavara, Alessandro Persona, Fabio Sgarbossa. Sustainable Packaging Development for Fresh Food Supply Chains [J]. Packag. Technol. Sci., 2016, 291.

[3] Shi, G. H. Research on the Fresh Agricultural Product Supply Chain Coordination with Supply Disruptions [J]. Discrete Dynamics in Nature and Society, 2013, 22(5): 655-664.

[4] Wei Chen, Lina Wang. The Study of Information Service in "Agricultural and Supermarket Docking" Mode [J]. China's Agricultural Science and Technology Leader, 2013, 15(5): 80-86.

[5] Yang A.T, Zhao L. D. On the role of revenue-sharing contracts in supply chains [J]. Operations Research Letters, 2013(39): 28-31. 
[6] Cachon, Karl. Supply chain coordination and setup cost reduction in case of asymmetric information [J]. OR Spectrum, 2013, 6(33): 99-122.

[7] Leat, P., \&Revoredo, G. C. Risk and Resilience in Agri-food Supply Chains: The Case of the ASDA Pork Link Supply Chain in Scotland [J]. Supply Chain Management: An International Journal, 2013, 18(2): 219-231.

[8] Thijs Defraeye, Bart Nicolai, Wayne Kirkman, Sean Moore, Sonnica van Niekerk, Pieter Verboven, Paul Cronjé. Integral performance evaluation of the fresh-produce cold chain: A case study for ambient loading of citrus in refrigerated containers [J]. Postharvest Biology and Technology, 2016, 112.

[9] Heng Luo, Minjie Zhu, Sengang Ye, Hanping Hou, Yong Chen, Larissa Bulysheva. An intelligent tracking system based on internet of things for the cold chain [J]. Internet Research, 2016, 262 .

[10] Sterling, David M. Cold Chain Management Tools: Assessments and Audits [J]. Food Logistics, 2013, 146. 